\title{
Thyroid Malignancy in Long Standing Multinodular Goitre: A Case Series with Review of Literature
}

\author{
Manjiri M. Makde, Meherbano M. Kamal*, Tulsi S. Chhadi and Prajakta R. Sathawane \\ Dept. of Pathology, Govt. Medical College, Nagpur, Maharashtra, India.
}

\begin{abstract}
Clinical presentation of patients with multinodular goitre is variable. Fine-needle aspiration (FNA) has been widely accepted as an initial step in the management of thyroid nodules. However, the usefulness of FNA to assess the risk of malignancy in thyroid nodules occurring within a long standing multinodular goitre (MNG) has not been completely clarified. Moreover, an unresolved issue is whether MNG is significantly associated with malignancy. MNG had been traditionally thought to be at a low risk for malignancy as compared to a solitary thyroid nodule (STN). However, review of literature showed no statistical difference in incidence of malignancy in both MNG and solitary nodular goitre. The incidence of malignancy in multinodular goitres has been found to vary from $7.5 \%$ to $17 \%$. The duration of the associated goitre varies and ranges from the shortest of one month to the longest of more than 20 years. Considering this background, we are reporting a series of three cases of thyroid malignancies diagnosed on FNAC in patients having long standing goitre.
\end{abstract}

Keywords: Thyroid Malignancy, Longstanding Multinodular Goitre, Review Of Literature

\section{Introduction}

Clinical presentation of patients with multinodular goitre is variable. Fine-needle aspiration (FNA) has been widely accepted as an initial step in the management of thyroid nodules ${ }^{[1]}$ It is relied upon to distinguish benign from neoplastic thyroid nodules, thus, influencing therapeutic decisions. ${ }^{[2]}$ However, the usefulness of FNA to assess the risk of malignancy in thyroid nodules occurring within a longstanding multinodular goitre (MNG) has not been completely clarified. ${ }^{[3]}$ Ultrasonography, an imaging study of choice for thyroid gland, provides accurate measurements of the nodular diameter for interval monitoring if needed. Additionally it allows characterization of nodules by sonographic features such as solid appearance, increased vascularity, micro-calcifications, irregular margins, all of which suggest malignancy. ${ }^{[4]}$

MNG is one of the common presentations of various thyroid diseases. A long standing unresolved issue is whether MNG is significantly associated with malignancy. MNG had been traditionally thought to be at a low risk for malignancy as compared to a solitary thyroid nodule (STN). However, review of literature showed no statistical difference in incidence of malignancy in both MNG and solitary nodular goitre. ${ }^{[5]}$ Several studies have suggested that the frequency of carcinoma in nodular goitres is about $25-60 \%$ of that in solitary nodules whereas incidence of malignancy in multinodular goitres has been found to vary from $7.5 \%$ to $17 \% .{ }^{[6]}$ The duration of the associated goitre varies and ranges from the shortest of one month to the longest of more than 20 years. ${ }^{[7]}$ Considering this background, we are reporting a series of three cases with the aim to see whether FNAC in a patient with recent development of new clinical symptoms can help in detecting malignancy in long standing MNG.

\section{Case Reports}

Case 1: This was a 47 years female who gave history of Thyroid swelling since 15 years. Patient was a known case of Thyrotoxicosis and was taking treatment for the same. She also gave history of discontinuing this medication against medical advice some time back. She came to us because she observed sudden increase in the size of the longstanding thyroid swelling since the last 3 months. On examination, a $5 \times 4 \mathrm{cms}$ firm thyroid swelling on right side was noticed. USG findings were hyperechoic nodule in right lobe of thyroid with central anechoic component $(0.9 \times 0.8 \mathrm{~cm})$ suggestive of colloid goiter. USG guided FNAC was done from both cystic and solid areas. Smears from cystic area showed scanty colloid along with follicular cells. Whereas smears from surrounding solid area showed abundant cellularity comprising of small groups and sheets of plasmacytoid cells scattered singly and also arranged in a follicular pattern. Anisonucleosis and binucleation was seen. Individual cells showed red cytoplasmic granules on May-Grunwald Geimsa (MGG) stain. Amorphous acellular hyaline material and dense amorphous clumps (suggesting amyloid like material) surrounded by tumour cells was also seen (Figure 1). Our cytologic diagnosis was Medullary Carcinoma of Thyroid. Thyroidectomy was done, which confirmed the cytologic diagnosis (Figure 2).

Case 2: A 35 years female presented with a swelling in left sided thyroid swelling since 20 years. She had another swelling on right side of neck since 1 year. The thyroid 
nodule was $4 \times 3 \mathrm{~cm}$, was firm to hard and moved with deglutition. Multiple firm to hard lymph nodes on right side of the neck formed a mass of $7 \times 6 \mathrm{~cm}$. USG showed enlarged left lobe of thyroid gland with heterogenous echo texture. Evidence of another well-defined hypoechoic lesion was seen on right side of midline extending into superior mediastinum. All these features were suggestive of neoplastic lesion in left lobe of thyroid with cervical lymphadenopathy. USG guided FNAC showed cellular smears comprising of groups, sheets and singly scattered spindle shaped and plamacytoid cells with anisonucleosis and hyperchromasia. Patches of amyloid in the form of dense amorphous hyaline material surrounded by tumor cells were also seen (Figure 3). Diagnosis was given as Medullary carcinoma of thyroid. Thyroidectomy was done, which confirmed the cytologic diagnosis (Figure 4).

Case 3: This was a 58 years male patient who presented with anterior neck swelling of 30 years duration. He

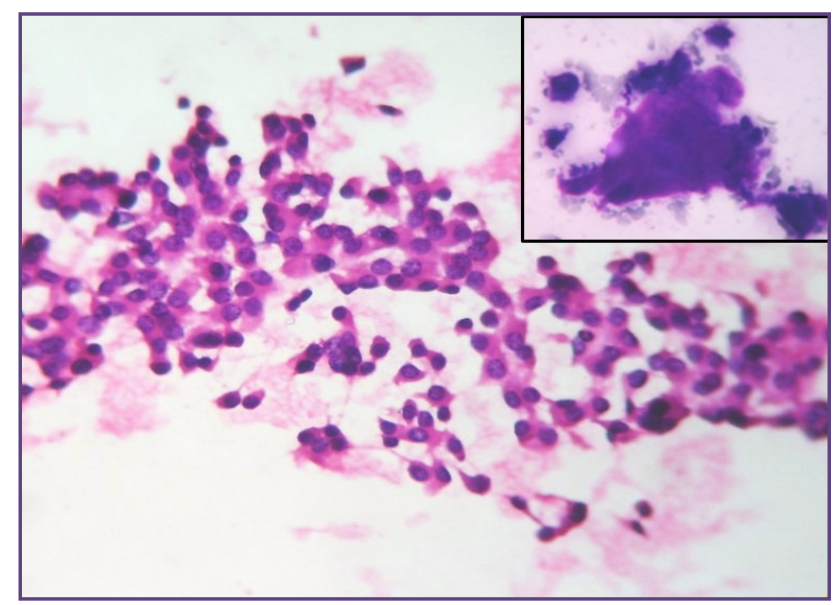

Fig. 1: (400x): Smears showing plasmacytoid cells along with amorphous hyaline material; H\&E (inset; MGG).

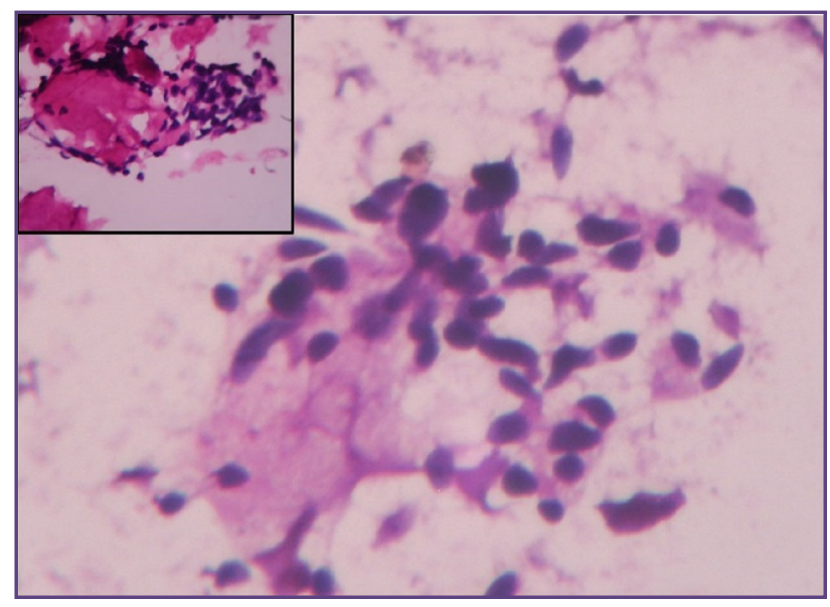

Fig. 3: (400x): Smears show spindle and plasmacytoid cells along with pink, amorphous hyaline material (inset); H\&E. recently observed change in voice since 1 month. The swelling moved with deglutition and measured $12 \mathrm{x}$ 11 x $8 \mathrm{cms}$. CT scan showed an ill-defined soft tissue lesion on right side of thyroid and the left lobe could not be visualized separately. Calcification was seen within the lesion. The lesion was seen extending into superior mediastinum displacing neck muscles and larynx and pharynx. CT impression was a malignant lesion of right lobe of thyroid with lung metastasis. USG guided FNAC smears were cellular and showed sheets and groups of round to oval bizarre cells having high $\mathrm{N}: \mathrm{C}$ ratio, irregular nuclear membrane and prominent punched out nucleoli (Figure 5). Binucleate and multinucleate tumor giant cells were seen. Also seen were singly scattered keratinized squamous cells with dense pyknotic nuclei (Figure 6). Background showed keratinous and necrotic material. Our cytologic diagnosis was anaplastic carcinoma of Thyroid with squamous differentiation. Patient was inoperable, hence, thyroidectomy was not done.

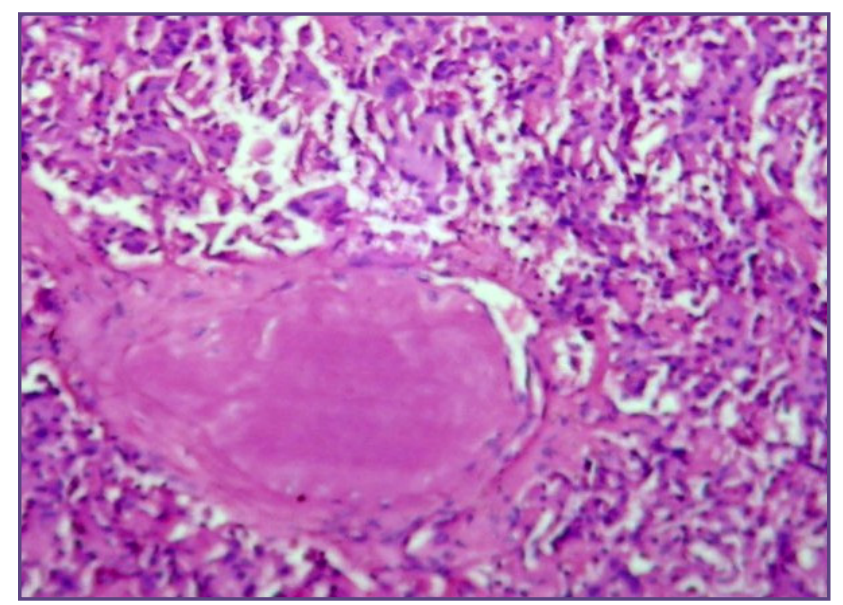

Fig. 2: (400x): Section showing dense amyloid material surrounded by tumour cells; H\&E.

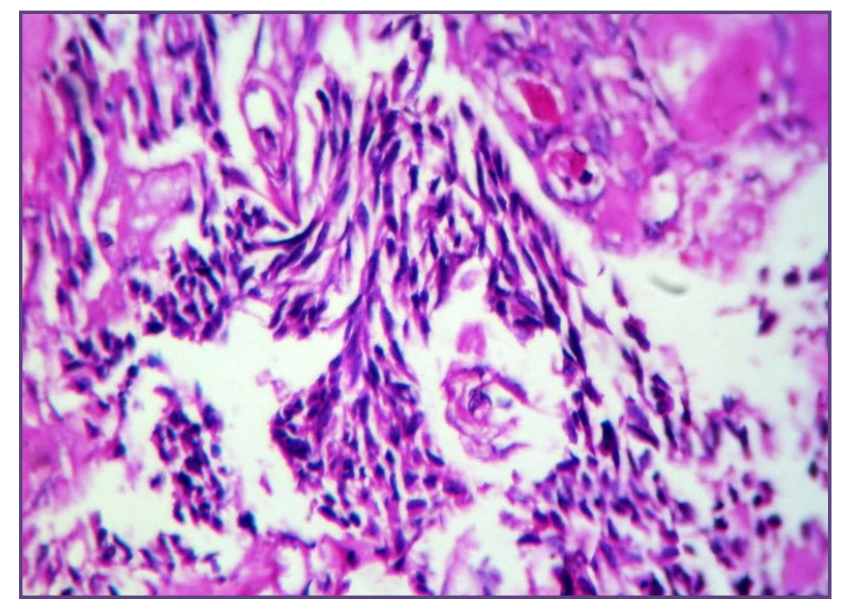

Fig. 4: (400x): Section shows spindle to round tumour cells. Amyloid is seen in right upper corner; H\&E. 


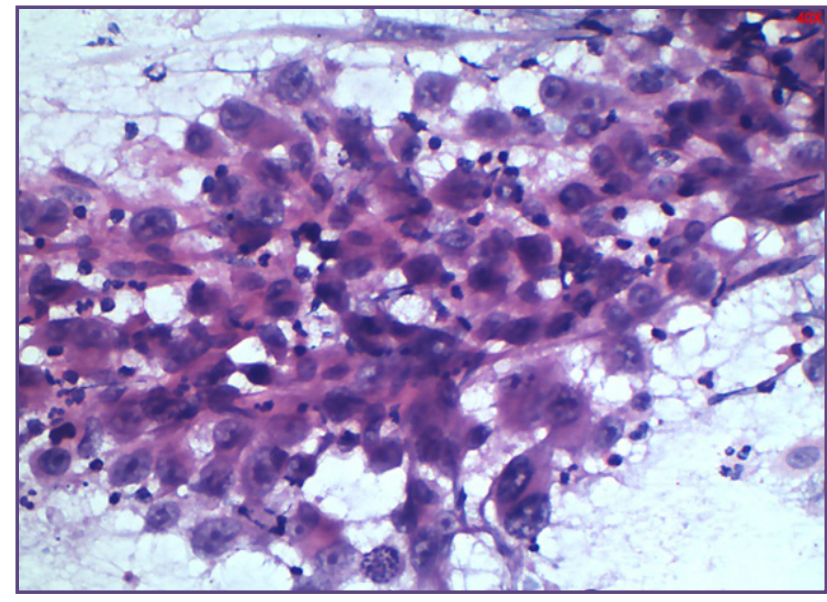

Fig. 5 (400x): Smear shows sheets of round to oval bizarre cells with high $\mathrm{N}: \mathrm{C}$ ratio, irregular nuclear membrane and prominent punched out nucleoli; H\&E.

\section{Discussion}

FNAC under USG guidance is a useful diagnostic modality in the evaluation of thyroid nodules in patients with MNG. Because the risk of thyroid malignancy in these nodules is comparable to that which exists in solitary thyroid nodules, the possibility of thyroid malignancy should be considered in all patients with $\mathrm{MNG}^{[8]}$ In our case series all the three patients had thyroid malignancy in long standing multinodular goitre.

In surgical series of Mc Call et al, they found a $17 \%$ incidence of malignancy in patients with solitary thyroid nodules compared to $13 \%$ in patients with nontoxic multinodular goiter and this difference was not statistically significant. ${ }^{[9]}$ Franklyn et al reported an incidence of malignancy of 5-9 \% and 1-4 \% in patients with solitary thyroid nodule and with multinodular goiter respectively. ${ }^{[5]}$

The age range of our patients was 30 to 60 years of age. Hanumanthappa M.B et al in their study reported $3^{\text {rd }}$ to $4^{\text {th }}$ decade as the most common age group. ${ }^{[10]}$ The duration of the goitre in all our three cases was between 15 to 30 years. $\mathrm{K}$ Sothy et al in their study have reported the duration of goitre ranging from lowest 5 years to longest more than 20 years. ${ }^{[7]}$ All our cases were asymptomatic until their recent complaints of sudden increase in size, change in voice and development of lymphadenopathy. Any such recent change in signs and symptoms in long standing goiters should raise the suspicion of a malignant change. ${ }^{[10]}$ Various studies conducted so far reported papillary carcinoma as the most common malignancy in long standing goitre. ${ }^{[10]}$ None of our cases were papillary carcinomas, instead FNAC diagnosis was Medullary carcinoma in two cases and one case was of anaplastic carcinoma. K Sothy et al in their study reported two cases of medullary carcinoma and two

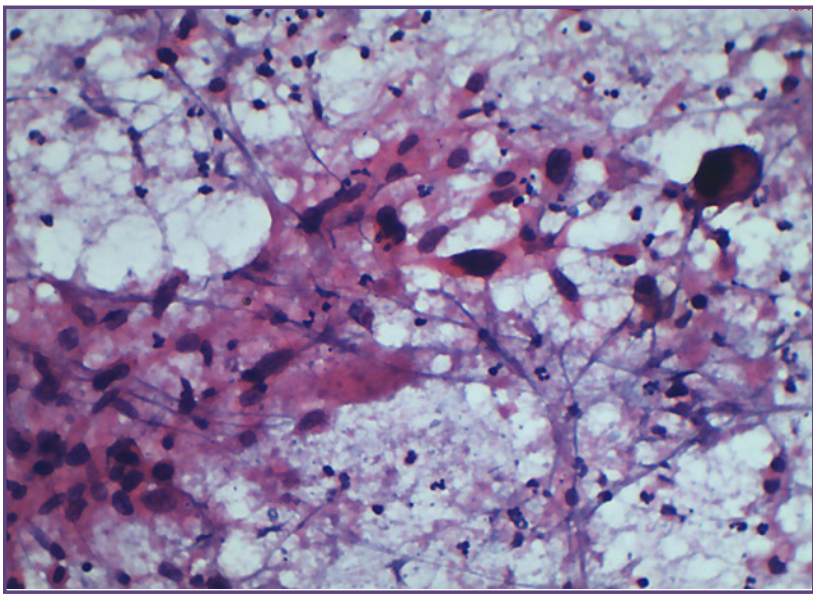

Fig. 6 (400x): Smear shows singly scattered keratinized squamous cells with dense pyknotic nuclei; H\&E.

were anaplastic carcinoma. ${ }^{[7]}$ Histopathological diagnosis was available in first two cases of medullary carcinoma. However in the remaining one case, histopathological diagnosis was not available as patient was inoperable.

Review of literature shows many studies that were conducted to observe, compare and detect the thyroid malignancy in MNG and solitary thyroid nodule (STN) using FNA smears and later confirmed by histopathology and some on thyroidectomy specimens alone. Studies have been conducted wherein comparison was done between USG guided FNAC findings in the preoperative assessment of the thyroid nodules and the results of thyroidectomy specimens. Studies in both the groups were conducted in many geographical regions (e.g., USA, Spain, France, Italy, Croatia, Turkey, Saudi Arabia, and India). In the first group, the occurrence of malignancy in $\mathrm{MNG}$ ranged from $5-36 \%{ }^{[4,8,11,12]}$ In the second group of studies, the occurrence of malignancy in MNG was $4.1-18.9 \%$. $[9,14,15]$

Studies have also been conducted to assess FNAC results on dominant, suspicious and non-dominant nodules of MNG. Nadir et al in their study of 42 cases of histopathologically proven MNGs, observed that, 15 (35.7\%) non-dominant nodules and $27(64.2 \%)$ dominant nodules harboured malignancy. Therefore, the risk of malignancy in nondominant nodules in MNG should not be underestimated and attention should be paid to non-dominant nodules that appear suspicious on USG. ${ }^{[16]}$ On the contrary, there are studies documenting that nodules harbouring malignancy or suspicious of malignancy in MNG cannot be distinguished clinically or radiologically. ${ }^{[17]}$ In that scenario the decision to select a nodule to perform FNAC becomes difficult. This in turn makes the early detection of cancer in MNG a very difficult task. A high index of suspicion needs to be practiced 
while reporting FNAC smears from longstanding goiters specially when there is a history of sudden change in clinical signs and symptoms. However, there are studies suggesting that FNAC may not be good enough for sampling associated malignancy, because of the problem of limited sampling or targeting of the lesion in all cases of MNG. This may lead to false negative diagnosis of an associated malignancy with $\mathrm{MNG}^{\left[{ }^{[12]}\right.}$ To conclude, malignant association in a long standing MNG is known and therefore a high index of suspicion, while reporting FNAC smears, helps in detection and diagnosis of these malignancies especially when there is any recent development in signs and symptoms.

\section{Funding}

None

\section{Competing Interests}

None

\section{References}

1. M Salih Deveci, Güzin Deveci, Virginia ALiVolsi, and Zubair W Baloch. Fine-needle aspiration of follicular lesions of the thyroid. Diagnosis and follow-Up. Cytojournal. 2006;3:9.

2. Nguyen GK, Lee MW, Ginsberg J, Wragg T, Bilodeau D. Fine-needle aspiration of the thyroid: an overview. Cytojournal. 2005;2:12.

3. Mazzaferri EL. Management of a solitary thyroid nodule. N Engl J Med 1993;328:553-9.

4. Frates $\mathrm{MC}$, Benson CB, Doubilet PM, Kuneuther E, Conterase M, Cibas ES, et al. Prevalence and distribution of carcinoma in patients with solitary thyroid nodules on sonography . J ClinEndocrinol. Metab. 2006;91:3411-7.

5. Franklyn JA, Daykin J, Young J, Oates G D, Sheppard M C. Fine needle aspiration cytology in diffuse multinodular goiter compared to solitary thyroid nodules. BMJ 1993;307:240.

6. Nadeem K, Akhtar N, Tarar JM. Thyroid malignancy in multi nodular goiter; incidence, a retrospective study in southern punjab. Professional Med J 2013;20:587-590.

7. K. Sothy, M. Mafauzy, W.B. Wan Mohamad, B.E. Mustaffa. Carcinoma of thyroid - clinical presentation and outcome. Med. J. Malaysia. 1991;46.
8. Tollin SR, Mery GM, Jelveh N, Fallon EF, Mikhail M, Blumenfeld W, Perlmutter S. The use of fine-needle aspiration biopsy under ultrasound guidance to assess the risk of malignancy in patients with a multinodular goiter. Thyroid. 2000;10:235-241.

9. McCall A, Jarosz H, Lawrence AM, Paloyan E. The incidence of thyroid carcinoma in solitary cold nodules and in multinodular goiters. Surgery. 1986;100:1128-1132.

10. Hanumanthappa. M.B, Gopinathan S, Rithin Suvarna, Guruprasad Rai D, Gautham Shetty, Ashith Shetty, et al. The Incidence of Malignancy in Multi-nodular Goitre: A Prospective Study at a Tertiary Academic Centre. Journal of Clinical and Diagnostic Research. 2012;6:267-270.

11. Papini E, Guglielmi R, Bianchini A, Crescenzi A, Taccogna $\mathrm{S}$, Nardi F et al. Risk of malignancy in nonpalpable thyroid nodules: predictive value of ultrasound and color-Doppler features. J Clin Endocrinol Metab. 2002;87:1941-6.

12. Ríos A, Rodríguez JM, Galindo PJ, Montoya M, Tebar FJ, Sola $\mathrm{J}$ et al. Utility of fine-needle aspiration for diagnosis of carcinoma associated with multinodular goitre. Clin Endocrinol. 2004;61:732-7.

13. Kojić Katović S, Halbauer M, Tomić-Brzac H. Importance of FNAC in the detection of tumours within multinodular goitre of the thyroid. Cytopathology. 2004;15:206-11.

14. Mathai V, Idikula J, Fenn AS, Nair A. Do long-standing nodular goitres result in malignancies? Aust $N$ Z J Surg. 1994;64:180-2.

15. Erbil Y, Barbaros U, Salmaslioglu A, Mete O, Issever H, Ozarmagan S, et al. Effect of thyroid gland volume in preoperative detection of suspected malignant thyroid nodules in a multinodular goiter. Arch Surg. 2008;143:558-63.

16. Nadir Paksoy, Kadri Yazal and Selin Çorak. Malignancy rate in non- dominant nodules in patients with multinodular goiter: Experience with 1,606 cases evaluated by ultrasoundguided fine needle aspiration cytology. Cytojournal. 2011;8:19.

17. Subhash CB, Manoj KS, Abhisheik MS, Subhabrata D, Ranjit B, Anower HH. Evaluation Of Incidence Of Malignancy In Multinodular Goitre. Journal of Evolution Medical and Dental Sciences. 2014;3:165-172.

*Corresponding author:

Dr. Meherbano M. Kamal, Address: MIG Colony, MA/8, Opposite Deekshabhoomi, Laxminagar, Nagpur- 440022 Maharashtra, India.

Phone: +91 9850489754

Email:dr.mmkamal@gmail.com

Financial or other Competing Interests: None. 